\title{
Los aportes de la pneumociencia de Teilhard de Chardin y de Quirce Balma para el actual problema de desespiritualización vivido en Occidente
}

\author{
Alejandro Vargas Carranza* \\ Recibido: Julio 2012 • Aceptado: Agosto 2012
}

En homenaje al Dr. Quirce Balma QDDG (2012)

\begin{abstract}
RESUMEN
El problema de des-espiritualización en Occidente conduce a la necesidad de procurar una des-cosificación del ser humano, la cual puede lograrse desde una pneumociencia, presentada en el pensamiento profético-pneumocientífico de Teilhard de Chardin y de Quirce Balma, con la implicación de dejar atrás el discurso teológico desde la pneumatología.
\end{abstract}

Palabras clave: pneumociencia, profetismo, ciencia, religión, des-espiritualización, cosificación.

\begin{abstract}
The problem of despiritualisation in Occident leads to the necessity to seek a dereification of the human, that (human, which) can be accomplished from a pneumoscience, presented in Teilhard de Chardin and Quirce Balma, with implies leave behind the theological discourse from the pneumatology.
\end{abstract}

Key words: pneumoscience, prophetic, science, religion, despiritualisation, reification.

* Bachiller en Teología del Convenio UNA-UNED, Bachiller en Filología Clásica en la Universidad de Costa Rica. Estudiante de Licenciatura en Teología en la UNED y de Licenciatura en Filosofía en la Universidad Nacional. También cursa la carrera de Derecho en la Universidad de San José.

E-mail: alejvargasc@yahoo.com 


\section{Introducción}

En la modernidad confluyen ciencia y religión para generar un amplio espectro, del cual nace la pneumociencia aunque con evidente carencia de una debida identificación, por lo que resulta necesario determinar su consistencia y función ${ }^{1}$. Por ello, en este caso, la pneumociencia es presentada en relación con los pensamientos de Teilhard de Chardin y de Quirce Balma como si fuese una larga astilla de un grueso tronco ${ }^{2}$.

Lo enigmático de la confluencia del Espíritu y la Ciencia surge de la oscuridad derivada de la novedad del abordaje temático ante la clásica desatención dada entre el místico-religioso y el objetivistacientífico. Clarificar esta oscuridad consiste en traer a los ojos un nuevo acuerdo ${ }^{3}$, del cual emerge la integración necesaria para lograr una solución a la enajenación humana vivida en los objetos: la cosificación del ser humano ${ }^{4}$.

1. El "cómo primero" consistente en explicar la pneumociencia.

2. El "cómo segundo" del determinar los elementos pneumocientíficos en estos dos hombres constituye sólo una muestra.

3. Con este traer a los ojos se manifiesta el "cómo tercero" de señalar las repercusiones de la pneumociencia teilhardiana y quirceniana en el actual problema de desespiritualización vivida en Occidente.

4. Problema como bien se ve en el griego "problema (balo)", lo que se tiene por delante.
Así como el biólogo, el paleontólogo y el geólogo toman una muestra del suelo para mirar lo que compete a su disciplina, del mismo modo se considera el pensamiento de los citados autores para conocer algo de lo mucho que está y así desear, con lo percibido, una confirmación de lo esperado, que no por eso deja de ser imprevisto. Proceso inductivo de no muy distinto matiz de aquel de la deducción, en cuanto lo general se sustenta a lo específico y viceversa ${ }^{5}$. Tal vez arriesgando de esta forma el rigor exigido por quien se torna bélico contra lo nuevo, aunque proveniente del caos primigenio del Espíritu para derrumbar los castillos de aire en los que construye el homo sapiens sapiens ${ }^{6}$.

Por lo indicado, cabe advertir la posibilidad de incomodidad ante el hecho de tener que dejar un confortable asentamiento pneumatológico para embarcarse en el mar

5. El percatarse de que la existencia existe implica el ir y venir, de la partícula al todo y su retorno.

6. Seguridad que en realidad es perversión. "Como condición de Homo Sapiens Sapiens, Homo Sapiens, tendría dificultad en poder lograr su desarrollo de «ser religioso», a consecuencia de la aparición de una lingüística pervertida. Los impedimentos a la locura de parte de lo cívico puede sí lograr establecer la verdad de su perversión como congruente con lo legal" (Quirce Balma, El Señor..., 1994: 153). También, cfr. 1 Co. 1,21. 
de la experiencia en una nao pneumocientífica. Máxime cuando hay tan poca luz y quienes la arrojan son dos hombres de ciencia y a la vez comprometidos con el espíritu: uno sumamente enigmático, de más de medio siglo de haber dejado su cuerpo físico; y otro, un sabio de la mística y de los enteógenos en avanzado proceso "de ocurrir del florecimiento de las flores como el fin de ésta", a la vez que trata de hacer ver la necesidad de que en esta aldea costarricense se llegue a amar al otro en isla de los "chunches" (Quirce Balma, El Señor Dios Príncipe de las flores, 1994: 153).

La reflexión pneumocientífica de estos hombres se presenta como un viento recio que proviene de otro superior (Jn., 3.8) y su hallazgo puede socavar la seguridad de los edificios fundados en la incompatibilidad entre ciencia y la religión, y reta para buscar más de lo que mucho ofrece la Vida. De la Vida a la teilhardiana, la "Vida al cuadrado", de esa Noosfera que implica conocer la Realidad profundamente y sin límites metodológicos, que impiden el percatarse plenamente del mundo, tal y como lo trama la perversa política en las personas para establecer engranajes del mecanismo-poder en lugar de seres auténticamente cosmopolitas. El Milieu teológico, el Reino de los Cielos, la Sociedad de los poetas, clama por un ser humano sistémico, ecuménico, actuante como edificador en la Piedra angular. Conocerla es mirar al Espíritu, sin este conocer anticipado no hay poiesis ${ }^{7}$.

Problema no despreciable al sujeto seguro en su tierra, pues el Espíritu lo conduce a un mar profundo de aguas inexploradas tal como un viento que empuja la barca de un expedicionario insaciable hacia hídricos parajes desconocidos, con el fin de hacer poesía ${ }^{8}$. Aquí el Corazón de la Materia es encontrado, la consistencia última del universo, el telos cósmico. En la omegaización percibida no hay divorcio entre ciencia y religión: la pneumociencia es una sola

7. Aquí cabría recordar que la facultad del conocer antecede la de actuar creativamente, la libertad implica la danza de ambas: Saber para saber..., saber para poder..., poder más para actuar más..., actuar más para llegar a ser más (Teilhard, El fenómeno humano, 1974: 301-302).

8. El dinero y la fama, auri sacra fames (Virgilio, Eneida, III, 56), se tornan insuficientes. Se da la presencia de una fuerza que mueve la barca humana que no es el deseo de guardar lo que se tiene, sino la esperanza hacia un futuro ilimitado más allá de sí mismo. "The force that is at this moment driving man out on to the high seas is not the simple desire to keep what he already has... the modern man has put his interest and hopes in an unbounded destiny beyond himself" (Teilhard, Human Energy, 1972: 164). También "' [d]esde este punto de vista, el Descubrimiento y la Síntesis intelectuales no son ya sólo especulación, sino creación" (Teilhard, Human Energy, 1972: 301). 
carne (Gn. 2, 24), nuptiae religionis et scientiae .

De esta primigenia, pero a la vez innovadora manera de conocer, se toma el objeto de esta investigación, invitación a las bodas entre el Espíritu y la Materia, el Ser y el Ente, Dios y la Humanidad (Mt. 22,1-14; Ap.19, 7-8). Constituye un punto de partida que no pretende acabarse en Teilhard de Chardin y en Quirce Balma. Por esta razón, visualizada la pneumociencia, en segundo proceder se ha de tomar al místico jesuita y luego al investigador profeta de esta aldea.

\section{La laguna de la pneumociencia}

Viendo el agua vi como aquellos diversos lirios crecían nutridos de misterio en aquella laguna. ¡Qué misterio, cuánta fuerza! La tarde cae y el frío nocturno se asoma al tuétano con la brisa, pero sé que el ocaso trae el deseo del alba, como la agonía invoca ante la muerte al Espiritu para una vida plena. Lleno de vida me siento Heracles.

A orillas de la laguna nació este deseo.

9. La unión en una sola carne no implica concordismo sino coherencia. Teilhard de Chardin menciona que la religión y la ciencia no deben ser mirados, en la esfera mental, como dos meridianos diferentes inseparables, error concordista; pero sí dos meridianos que necesariamente deben reencontrarse en algún polo de visión común, coherencia (Teilhard, El Corazón de la Materia, 2002: 153).

\section{La pneumociencia}

En sentido estricto, la pneumociencia -desde la etimologíaindica una alusión al Espíritu y al conocimiento objetivo-científico que culmina en des-velación. La palabra consta de la partícula griega pneuma, que remite al concepto judaico del ruaj y al latino spiritus, indicando en castellano la noción de Espíritu; a su vez esta palabra consta de una derivación latina del término scientia, sustantivo relacionado estrechamente con el verbo latino scire, aludiendo al saber propio de las ciencias positivas.

La indicada etimología resulta sencilla, incluso ingenua en vista de la polisemia que se yergue como Hidra de Lerna, dominada por Heracles debido a la previa visualización de sus múltiples cabezas. Por ello, en vista de las diversas acepciones de la ciencia, se propone comprenderla evolutivamente desde el pensamiento teilhardiano, que divide la historia científica en esoterismo, esteticismo y curiosidad, etapas que anteceden a la mística moderna de descubrimiento (Teilhard, Human Energy, 1972: 165). Previa a esta última etapa es que se presenta la Ciencia actual, presa de la producción y el armamento ${ }^{10}$.

\footnotetext{
10. "Pegaso pasó a ser un animal de tiro que reclama ser descubierto como una forma esencial de acción" (Teilhard, El fenómeno humano, 1974: 338).
} 
Razón por la cual, después de casi dos siglos de luchas apasionadas, ni la Ciencia ni la Fe pudieron llegar a disminuirse entre sí, más bien "la ciencia y la religión llegan al punto de necesitarse mutuamente para lograr su desarrollo" para dar paso a esta mística moderna de descubrimiento (Teilhard, El fenómeno humano, 1974: 343).

Por tanto, la Ciencia es vista en evolución para unirse con la Religión con el fin de permitir una comprensión y vivencia plena de la Realidad. En efecto, "Religión y Ciencia: las dos caras o fases conjugadas de un mismo acto completo de conocimiento, el único que puede abrazar, para contemplarnos, medirlos y acabarlos, el Pasado y el Futuro de la Evolución" (Teilhard, El fenómeno humano, 1974: 345). Esta forma de proceder es lo que el Dr. Quirce Balma ha denominado pneumociencia, concepto que implica la confluencia de dos formas de ver el mundo que estaban distanciadas (Vargas, 2011: 1).

Este criterio también puede ser entendido desde una amplia semántica del término scientia. Desde el alma de la ciencia, el saber implica "saborear" profundamente lo existente, lo tangible, hecho que equivale al ver teilhardiano ${ }^{11}$,

11. “... ¿qué es lo que le sucede al paseante si la circunstancia le lleva a un punto naturalmente privilegiado (encrucijada de caminos o de valles), desde el cual no ya sólo la facultad que de no ser ejercida conduce a la muerte. "Ver o perecer", la vida consiste en un acrecentamiento de conciencia, de visión, para que crezca la unidad (Teilhard, El fenómeno humano, 1974: 43). De este modo, la Ciencia es ver (discernir cada vez con más claridad) y la Conciencia es visión, nacida de la Materia, en torno a lo humano, en dirección a algo Ultra-Humano (Teilhard, El Corazón..., 2002: 49).

En este sentido se reflexiona, pasando de la simple vida a la "Vida al cuadrado", para generar una discontinuidad entre Bio- y Noosfera (Teilhard, El Corazón..., 2002: 49). Así la Reflexión humana alcanza a entrever el Omega ${ }^{12}$, parcialmente actual y parcialmente transcendente, es decir, aquella es el punto que emerge sobre la humanidad organizada, no sobre la confluencia de individuos, y entrevé el Universo perfectamente unificado, "Centrum super centra" (Teilhard, La activación de la energía, 1967: 113). Este estado constituye el ámbito pneumático, espiritual ${ }^{13}$.

mirada, sino las cosas irradian? Es entonces cuando, al coincidir el punto de vista subjetivo con la distribución objetiva de las cosas, se establece la percepción en toda su plenitud. El paisaje se descifra y se ilumina. Se ve." (Teilhard, El fenómeno humano, 1974: 44).

12. Foco o polo de síntesis universal (Teilhard, La activación de la energía, 1967: 101).

13. En este sentido, cuando se ve conscientemente no existe contraposición entre Materia y Espíritu, puesto que "no son dos 
Cabe añadir que dicho estado pneumático incluso es distinguido lingüísticamente en la Biblia. Los términos pneuma o rûah se diferencian de psichê o nefes ${ }^{14}$, en donde los primeros remiten a los aspectos de la conciencia humana que yacen en conexión con Dios; mientras que los segundos implican la conciencia en la cotidianeidad ${ }^{15}$. Esta distinción lingüística veterotestamentaria nutre el pensamiento del

cosas, sino dos estados, dos rostros de una misma trama cósmica". La Materia es matriz del Espíritu y éste el estado superior de la Materia. "El Espíritu, lejos de ser antagonista o antípoda, era el mismo corazón de la Tangibilidad a la que yo trataba de llegar" (Teilhard, El Corazón..., 2002: 28,38).

14. La disyunción marca la diferencia lingüística entre el griego y el hebreo, pero a la vez implica el mismo vértice semántico.

15. "El rûah en el hombre retiene su conexión inmediata con Dios, para denotar la dimensión 'superior', que tiende hacia Dios, en la existencia humana (p. ej.: Esd. 1.1, 5; Sal. 51.12; Ez. 11.19), mientras que 'nefeš' tiende crecientemente a representar los aspectos más terrenales o "inferiores" de la conciencia del hombre, la vida personal pero meramente humana del hombre, el asiento de sus apetitos, emociones y pasiones (usado así regularmente). De este modo el camino está preparado para la distinción paulina más neta entre lo psíquico y lo espiritual (1 Co. 15.44 46) [...] El gr. 'psichê', término correspondiente a 'nefeš' en el Nuevo Testamento, aparece en los evangelios con significados similares, pero en ciertos casos, en los que indica vida, incluye más que la vida física, que cesa con la muerte (Mt. 10.39; Mr. 8.35; Lc. 17.33; 21.19; Jn. 12.25). En los cuatro evangelios 'pneuma', el equivalente de 'rûah', denota a veces el principio vital, si bien en otros casos significa el nivel más elevado de la vida psíquica." (Douglas, 2000, c1982) apóstol Pablo, quien establece en griego una clara distinción entre lo psíquico ordinario y lo psíquico supraordinario: pneumático ${ }^{16}$. Último estado vivenciado en la Ciencia de Teilhard de Chardin que mira al Espíritu desde la Materia.

\section{La pneumociencia entre ciencia y religión como entre Escila y Caribdis}

La pneumociencia puede ser confundida con disciplinas científicas, como la neuroteología, o religiosas, como la pneumatología. Se encuentra así entre la Ciencia y la Religión actuales, como entre Escila y Caribdis.

La ciencia moderna no ha desatendido el estudio del nivel trascendental de la conciencia humana. Desde la neurobiología ha logrado identificar alteraciones fisiológicas y biológicas cerebrales (producidas por estados de meditación), ha denominado espiritualidad a la experiencia emocional originada de la relación con lo transcendente ${ }^{17} \mathrm{e}$

16. "Para los aspectos superiores de la vida corriente, y especialmente la vida superior del cristiano, Pablo usa 'pneuma'. En este sentido hace uso de los adjetivos psyjikos y pneumatikos (1 Co. 2.14-15). Cuando se vale de 'psichê' juntamente con 'pneuma' (1 Ts. 5.23) está describiendo simplemente la misma parte inmaterial del hombre en su aspecto inferior y superior." (Douglas, 2000, c1982)

17. "La espiritualidad implica como su principio fundamental una conexión con algo más grande que uno mismo, que incluye una 
incluso ha señalado con objetividad los beneficios psicosomáticos de permanecer en vinculación con tal dimensión, principalmente en el manejo del estrés. A su vez, también ha denominado neuroteología a la disciplina que estudia el funcionamiento cerebral de una persona cuando se vincula con lo trascendente ${ }^{18}$.

A pesar a la valoración positiva de este ámbito, el enfoque científico todavía permanece algo restrictivo a lo religioso. El "hombre de ciencia" tiende a cubrirse de una aparente objetividad, muchas veces para disfrazar la intersubjetividad de una comunidad internacional que puede aceptar como verdad lo que a luz de la experiencia se muestra como falso ${ }^{19}$. Tampoco parece

experiencia emocional de temor y reverencia religiosa. La espiritualidad es por tanto, una experiencia individual y una relación con un aspecto fundamental, no material del universo, que puede ser referido en muchas formas- Dios, Poder Superior, la Fuerza, Misterio y lo Trascendente y constituye el medio por el que una persona encuentra su propio sentido y relación con la vida, el universo y todo lo que existe". (Mohandas, 2008: 63-64)

18. Entre diversa literatura al respecto, existe material excelente y abundante en tres volúmenes de Where God Sciencie Meet: How many Evolutionary Studies Alter Our Understanding of Religion, por Patrick McNamara (2006).

19. El método científico otorga al científico un instrumento poderosísimo para demoler lo que se pregona y no se ajusta a los hechos, pero no por eso ha dejado de ser presa de intereses económicos que han disfrazado existir en dicho enfoque una precisa distinción entre lo psíquico-cotidiano y lo psíquico-supracotidiano.

Por tanto, es conveniente tomar en consideración los términos distintivos de la sacra literatura judeocristiana, los cuales delimitan la experiencia psicológica vinculada con lo transcendente y aquella propia del diario vivir.

\section{El fluir de la laguna}

Teorizar, el ver de un dios creador que toma la madera necesitada de labor. Crear para adelante, ello lleva pensar sobre un objeto. Así este marco nace con una aporía. No hay paso, el problema nos deja sin camino, pero hay una presión inconmensurable, capaz de romper cualquier dique. No hay paso, pero el agua quiere fluir con vida. ¿Será un dique teológico? ¿No será nuestra civilización con necesidad de dejar su cascarón y evolucionar?

\section{De la pneumatología a la pneumociencia}

Cabe advertir que la pneumociencia puede confundirse con la pneumatología, disciplina teológica que parte del Espíritu y cuya problemática sustenta el nacimiento de

fabulillas como objetividad con fines estrictamente pecuniarios y no reveladores, p.e. la farsa del sida. Al respecto, La macroestafa del SIDA y el mito de la transmisión sexual, investigación de Luis Carlos Campos (2009). 
la misma pneumociencia. En Occidente, la pneumatología no tuvo mayor auge ${ }^{20}$, pues dejó de lado el Espíritu en sus tratados religiosos: su latir no se escuchó más y la atención se enfocó en la experiencia de la figura humana-divina de Jesús. De este modo, Occidente se tornó cristológico, mientras que Oriente fue más pneumatológico.

La explicación de dicho fenómeno pudo derivar de factores misopneumáticos ${ }^{21}$, subyacentes a la forma en que se manifestó el pensamiento en Occidente. Al respecto cabe indicar que el logos nació como una alegorización de lo mítico, pensamiento ligado a la sexua$\operatorname{lidad}^{22}$, y fue la base de creencias cristianas que despreciaron la materia $^{23}$, en la que ubicaron al cuerpo

20. "La teología de occidente, a diferencia de la oriente, no ha conocido un tratado doctrinal propio sobre el Espíritu en la fisionomía clásica de sus tratados dogmáticos" (Shûtz, 1991: 12).

21. Cabría pensar un misopsiquismo, desde una concepción aristotélica, en cuanto el alma es al cuerpo como el mito a la tragedia: el mito como estructura. El misopsiquismo se manifiesta como misomithía, pero en este caso la misopsiquismo es el de lo suprapsíquico, es decir misopneumático.

22. Ligamen que se pretende hacer a un lado alegorizando al mito a través del logos (Brenes, 2003: 47).

23. Generalizar no del todo es bueno, no falta la excepción, pero no por eso se ha de dejar el enmarcar la tónica. Aunque existiese Petronio y Sade, no por eso Cicerón y Kant dejarían de imponerse. A pesar de que la diabolización y la alegoría no fuesen siempre las mismas y entre ellas correlativas, las en asociación muchas veces con lo femenino ${ }^{24}$. El desprecio contra lo corporal, y en general contra la materia, no se dejó de lado con la ciencia moderna ${ }^{25}$, sino que perduró hasta que se efectuó una valoración positiva de la Materia como madre del Espíritu ${ }^{26}$. Con esta valoración Teilhard de Chardin consiguió visualizar el Omega.

Asimismo, logró conciliar la dicotomía del Espíritu y la Materia, en una auténtica pneumociencia (presente, de forma difusa, a lo largo de sua opera omnia) y que fue condensada principalmente en su trabajo de mayor madurez espiritual: "El Corazón de la Materia" (1950). De manera distinta al logos escolástico, Teilhard de Chardin utiliza un logos científico en contacto con el Omega. Esta última forma de proceder existía en el saber mítico, pero había sido dejada de lado por un logos moralizante.

líneas marcan en gran medida una superficie y un volumen manifiesto si son multiplicadas en entre sí.

24. En el Medievo la mujer es luciferina, diabolizada desde Orígenes hasta las tentaciones de San Antonio, aparecidas en el mismo tiempo que la teología agustiniana (Hinkelammert, 2003: 130).

25. Dios se mantuvo como certeza y el diablo como incerteza y ámbito de las pasiones, presentes todavía en el genio de Descartes (Brenes, 2002: 168).

26. Lo Femenino o lo Unitivo constituye el Espíritu ya, no como desmaterialización, sino como síntesis, Materia matrix (Teilhard, El Corazón..., 2002: 65). 
Teilhard de Chardin: El Espíritu desde la Materia

El Sentido de la Plenitud, Sentido de la Consumación y de la Compleción, constituye el polo atrayente ante la necesidad de "Algo esencial". El sabor particular de esta nota conduce el peregrinaje, el saber incomparable con las pasiones del alma -como los gozos del saber, descubrir, crear y descubrir-, es el principio metamórfico hacia un telos cósmico (Teilhard, El Corazón..., 2002: 17-18).

El llamado de la Materia es percibido desde los siete años por Teilhard de Chardin, su "yo" estaba atraído como imán al "Dios de Hierro", presente desde un arado hasta los fragmentos de metralla recogidos en un campo de tiro vecino. El Hierro poseía la Consistencia: el atributo fundamental del Ser, el Inalterable e Irreversible. Pero luego hace presencia la desesperación infantil, el Hierro se raya y oxida "Quod tinea non corrumpit" (Teilhard, El Corazón..., 2002: 2021). ¡Qué lejano se hallaba de Omega! Pero, a la vez qué certeza de no estar en lo correcto, error necesario para dar cabida a la aparición de lo Universal.

Surge, así, para Teilhard de Chardin un nuevo interés: el Mineral. El despertar a la "Trama de la Cosas", con sutileza se le manifestaba la Consistencia. De ahí su interés por la Geología y la Paleontología. No había llegado a la vida religiosa cuando ya seguía las huellas hacia una profunda metamorfosis. Junto al Mineral, semiaccesoriamente, el interés por la naturaleza vegetal y animal (Teilhard, El Corazón..., 2002, pág. 22). Se le devela la "Trama de las Cosas", desde el Mundo de Fuerzas hasta el de los Animales, pasando por el de las Piedras. Pero vaya problema, un Punto muerto: el panteísmo de efusión y disolución.

Al llegar a este Punto muerto la Materia habla desde su Corazón ${ }^{27}$. Se presenta la necesidad de fundirse con Todo, un sentimiento catalizado por el descubrimiento de la Evolución ${ }^{28}$ (Teilhard, El

27. ¿Tendría luego motivo Teilhard de Chardin para dedicarle un Himno? "Bendita seas tosca Materia, barro estéril, duro peñasco; tú que no cedes sino a la violencia y nos fuerzas a trabajar si queremos comer (...) Sin ti, Materia, sin tus ataques, sin tus desgarramientos viviríamos inertes, estancados, pueriles, ignorantes de nosotros mismos y de Dios (...) ¡Álzame, Materia, a las alturas, mediante el esfuerzo, la separación y la muerte; álzame allí donde sea posible por fin abrazar castamente el Universo! (...)" (Teilhard, El Corazón..., 2002: 81-82).

28. Así la Vida no es comprendida de forma aislada sino como parte de un proceso creativo del Universo, de manera que la Materia y la Energía junto a la Vida constituyen una alta tensión monista que enciende el Fuego que devoraba su Corazón y Espíritu (Teilhard, El Corazón..., 2002: 27). En efecto, el eco de la realidad, sustento de la vida, es escuchado primordialmente en los procesos creativos del Universo como los latidos del corazón 
Corazón..., 2002: 25-27). Desde la Evolución se comprende la espiritualización de la Materia, matriz del Espíritu, proceso originario de la Biosfera y luego de la Noosfera, la Humanidad totalizada, en la que se entrevé el Omega (Teilhard, El Corazón..., 2002: 28, 30, 38).

Sin embargo, la constatación de la Noosfera se da con la experiencia de la Guerra (Teilhard, El Corazón..., 2002: 33). En este punto el tratado del Corazón de la Materia funge como una llave de paso que remite al profetismo. Basta comparar la espiritualidad descrita por el autor con aquella propia de una persona profeta (p.e.: Jer. 20 7-9, Ez. 37 1-10), para percatarse de un camino, un método. El tener el Omega hacia adelante conduce a una reflexión sobre el actuar humano. Como profeta inicia a visualizar las fuerzas incoercibles de repulsión mutua y de materialización contrarias al esperado Espíri$\mathrm{tu}^{29}$. A pesar de ello no da lugar a la

del mundo (Avendaño, 2002, pág. 14), que en Teilhard de Chardin constituyen la zarza ardiente (Ex. 3, 2-3), es decir, aquello que está «En el Corazón de la Materia, Un Corazón del Mundo, El Corazón de Dios» (Teilhard, El Corazón..., 2002: 15).

29. "Tal como un polvo cuyos granos, a pesar de estar comprimidos, rehúsan entrar en contacto molecular, se excluyen y se repudian, en el fondo con todas sus fuerzas. A menos que, lo que sería peor, su masa se coagule de tal forma que, en lugar del esperado Espíritu, aparezca una nueva oleada de determinismo; es decir, de materialidad" [...] desesperación, sino a la reflexión. La falta de armonía muestra la perversión en las reglas de la Noogénesis. Lo manifiesto indica que se deben comprobar los cálculos para que la máquina humana deba actuar de manera que no engendre sólo Materia, sino que dé cabida a una sobreabundancia de Espíritu (Teilhard, El fenómeno humano, 1974: 310$)^{30}$.

\section{El profetismo pneumocientífico}

Al ver las aguas supe como su fluido era de llamas de fuego. Nada en ellas fue distinto al herir de una astilla. Pensé entonces: Profetas no son aquellos que prometen el cielo en la tierra, sino quienes viendo el cielo señalan el infierno en esta.

La neomateria superpuesta a todas las demás formas de Materia. El "Movimiento de Masas", el Millón de hombres agrupado en lo militar y en la fábrica, "todo encaminado, con el Comunismo y el Nacionalsocialismo, hacia la más espantosa de las agrupaciones. El cristal, en lugar de la célula. El hormiguero, en lugar de la Fraternidad". (Teilhard, El fenómeno humano, 1974: 309, 310)

30. "Cuanto más se reflexiona en esta cuestión, infinitamente urgente, de un plan de conjunto que hay que encontrar para construir la Tierra, tanto más nos damos cuenta de que, si queremos evitar el camino de la Fuerza material y brutal, no queda otra salida hacia adelante que la camaradería y la de la fraternidad, tanto entre los pueblos como entre los individuos. No hostilidad envidiosa, sino emulación. No sentimentalismo, sino espíritu de equipo" (Teilhard, La activación..., 1967: 19). 
El profetismo teilhardiano

La visualización del Omega como el grado más alto de Evolución promueve el profetismo teilhardiano. El profeta en cuestión, como una persona inspirada, mira el mundo desde y hacia Dios-Espíritu y su visión subyace en la desmaterialización, en el Corazón de la Materia. Muestra al Universo fluyendo hacia un estado omegaizador presente y futuro, en el cual el ser humano de forma inmediata logra mejorar su ser. De este modo, cuando intuye el Omega presenta una reflexión místico-científica (pneumociencia), que describe en sus diversos tratados a manera de estados alterados de consciencia.

Esta reflexión místico-científica destaca en su tratado "El Corazón de la Materia", que invita a dejar de lado prejuicios hacia lo científico, como bien abundan en los fundamentalismos, virus de letra, y no células de experiencia y pensamiento. A su vez, llama al científico a percatarse del todo convergente, del fin integral del universo, no inexperimentable, sino a la mano: en la tosca Materia. Por tanto, esta reflexión conduce a las siguientes apreciaciones:

a. El amor hacia la dinámica que confluye en el Omega conforma la danza entre Eros y Psique, vínculo liberador de las cadenas de Pegaso. Ante el ver teilhardiano se visualiza la Noosfera y al ser humano hecho presa del Perverso Colectivo, generador exclusivo de Materia y no de Espíritu. El cristal en vez de la célula. El mecanismo en lugar del sistema. Palabras eternas para elevación liberadora.

b. De las tuercas del reloj que mueven sus manecillas, cual hacha de verdugo calendarizador de la vida y el pensamiento, clama la voz desde lo más hondo de la Materia. No se trata de un deseo suprimible, al cual se le pueda tapar la boca, es parte de la Evolución, proceso inevitable: necesario hacia Omega. Hecho constatable en la experiencia, en la complejificación como conciencia, centramiento, consolidación por complejificación.

c. Evolución que hace cambiar lo inerte en organismo, que introduce un proceso metamórfico en los humanos alienados en la maquinaria productora de materialidad, con el fin de hacerlos auténticos cosmopolitas. Seres planetarios convergiendo en armonía sistémica y no esclavos de perversos colectivos de política y economía, bajo pancartas de falsa libertad socialista o liberal. 
d. Profetismo para la ruptura teórica y práctica en los límites metodológicos de la ciencia tradicional e invitación a dejar las creencias negadoras del pensamiento, presentes a la orden del día en miríadas de grupos religiosos. Omega y Evolución, fin y método, que ante los límites de la ciencia y las creencias religiosas empujan una metamorfosis noosférica, para un auténtico ecumenismo y no aquel eclecticismo de hijos de la noche que suman masas.

e. Diversidad en constante cambio y convergencia en un punto de centramiento, no deviene en negación de la autonomía, debido a que no es concordismo, sino coherencia: la unión en el erotismo que no por eso permite la negación de sus protagonistas. Así el profeta se manifiesta.

f. La apertura con pasión al Espíritu creador, de amar profundamente a la Materia como vientre del fruto espiritual. Deméter, la Tierra-Madre interpelada en Ciencia por el cuestionamiento de un fruto recién nacido en el Árbol de la Vida. Constituyen las palabras del profeta (Teilhard, El fenómeno humano, 1974: 173).

g. El dejar el misopneumatismo, como se abandonan las cargas abstractas de una preocupación malsana, posiciona la Ciencia en el Espíritu, desde y para éste. El rechazo de la moral restrictiva de la palabra que teme conocer la Vida, en su psiquismo: en su tensión monista con la Materia y la Energía. Así es el portavoz del Omega.

\section{Quirce Balma y el Señor Dios Príncipe de la Flores ${ }^{31}$}

La descrita sensibilidad profética también se presenta en el psicólogo y farmacólogo, Dr. Quirce Balma, principalmente en sus estudios sobre enteógenos y estados alterados de conciencia, indagaciones en las que es posible desentrañar la pneumociencia. De este modo, en coherencia con el pensamiento teilhardiano, propone que el sujeto debe alcanzar la experiencia mística para poder vincularse con los demás seres planetarios y así alcanzar la plenitud, la felicidad.

Quirce Balma desarrolla trabajos sobre el chamanismo en

31. Xochipilli, Dios Príncipe de las Flores, retorna de los muertos para una resurrección de las flores, para el extásis en cuanto entrada al "estadio de la conciencia en medio del estado de la conciencia de ser/antiser", ello para conseguir una nueva realidad, distinta a la propia en la relación entre materia como estructura del yo, y espíritu como hambre y sed de la compra y de su venta: de la absurda dicotomía de guardar y gastar por estar "haciendo" y siendo (Quirce Balma, El Señor..., 1994: 151, 152, 156). 
los que da énfasis a la herbología enteogénica y demás alucinógenos (arquetipos del pensamiento mítico-religioso), precursores de estados alterados de conciencia que se presentan junto a ritos $\mathrm{y}$ danzas. En estos estudios destacan características universales del chamanismo, aunque particularmente precolombinas ${ }^{32}$.

El chamanismo es mostrado como parte fundamental de la sociedad primitiva, la cual posee un fuerte vínculo con la naturaleza. La experiencia mística del chamán consiste en un contacto con

32. “... (a) adivinación y magia de climas y cultura, (b) contacto con el mundo de los ancestros, (c) magia de la cacería, (d) herbología y medicina indígena o nativa, (e) rituales, ritos, oraciones y sacrificios para atraer la lluvia y el buen tiempo y echar el mal tiempo de la agricultura, (f) el uso de diseño que contienen los cuatro puntos cardinales y un centro -entre los Navajos de los Estados Unidos y los Aztecas cada punto direccional era representado con un color distinto, ( $\mathrm{g}$ ) el uso de diseños basados en las religiones derivadas del dios rey Quetzalcóatl que comprenden tanto la culebra como las alas de un ave, (h) el contacto con el mundo de los dioses a través de una herbología enteogénica, danza y música ritualística adecuada para ello, (i) sacrificio de parte de las cosechas con la finalidad de traer bendiciones del cielo y del mundo de los ancestros, (j) servir a maestros de parte de aspirantes a nuevos chamanes, (k) dirigir obras de arte, música y teatro con la finalidad de impartir lecciones y obtener visiones y $(\mathrm{m})$ defender a las personas de los ataques de brujos, otros chamanes y espíritus malignos" (Quirce Balma, El chamanismo y las drogas enteogéncias/alucinatorias del mundo precolombino, 2010: 2). la realidad, pero de una forma más sistémica e indiferenciada con respecto a la construcción lógicomaterial que impera en la sociedad moderna, construcción presente a lo largo del pensamiento occidental. El sueño del chamanismo constituye el despertar anhelado por el ser humano moderno que abrió sus ojos al logos, que a pesar de su utilidad para la construcción de la civilización hizo que el ser humano olvidara que es parte de un todo y que necesita del otro. Por tal motivo, es necesario volver al mundo espiritual, incluso con ayuda de la ciencia, para la salud y plena realización de la existencia humana.

En su texto el Señor Dios Príncipe de las Flores (1994), destaca metafóricamente esta experiencia chamánica. Muestra el estado "normal" caracterizado fenomenológicamente por la contraposición entre lo tuyo y lo mío, que nutre el pensamiento del ser como real y dejar de ser como maldito a ser: el tener de un aquí y un allá en la ausencia de esto o de aquello y el antiser en pobreza ${ }^{33}$. En cambio, en lo alucinatorio, lo engrámico y lo arquetipal, se tiene el sentido en donde se es, fue y será simultáneo: el

33. Ciega visualización en cuanto el ser dado y el ocurrir constituyen un proceso, tal como se explica metafóricamente en chakras y flores. "No se deja de ser, se llega a conseguir una realidad" (Quirce, El Señor..., 1994: 150-151). 
ser así, mediante la concreción del ser y el antiser. El perder de vista el proceso lleva a la confusión entre lo mío como esto de yo y aquello como esto de vosotros, origen de la falsa demarcación propuesta por la paranoia. De modo que lo nuestro es una lucha entre lo mío y lo vuestro. Dilema solucionado por los Incas al establecer el poder como "aquello" donde lo "tuyo" no niega lo "mío", solución que cae al olvido por el "advenimiento del desastre en el pensamiento y el lenguaje adrede de lo experiencial" 34 (Quirce, El Señor..., 1994: 151).

Por tanto, en la actualidad se da el fenómeno de la materialización consistente en tener, para ser alguien en una sociedad de consumo $^{35}$. El ser humano se cosifica y es uno más entre los otros entes inanimados por un lado, en cuanto

34. La perversión de la "lingüística" consistente en ser definido por el hecho de definir, no es otra cosa que la filosofía de las flores que seca las flores. Es el no rotundo a un "pasar de aquí a un cuando fue allá" y la afirmación a sepultar el recuerdo, de existir como el hecho de la perspectiva del yo. Proceder de Tezcatlipoca cuando embriaga a Quetzalcoatl para llevarlo, por el reflejo de la mentira, hacia el refugio en la distancia de su corazón y de su jornada de los Toltecas, hecho que lo condujo a separase en partes, entre estas: Xochipilli, Dios Príncipe de las Flores (Quirce, El Señor..., 1994: 153, 156).

35. 'El 'tener' no es algo negativo: si la conciencia también lo es, no existe un antagonismo adonde existe demarcación, a no ser que haya un error entre lo mío y aquello" (Quirce, El Señor..., 1994: 151). son una especie de cristales, por otro "animados": en cuanto cristales movilizados en la maquinaria sociotecnológica. El ser humano se encuentra aislado en la isla de los chunches. Este es el Milieu materialista (Quirce, El Milieu..., 2011a).

La ruptura con el Milieu materialista inicia con el profetismo que proclama la vuelta a los estados alterados de conciencia, los cuales permiten visualizar la dimensión sistémica, en la cual es posible percatarse del otro y desprenderse del ego aislado, alineado y enajenado. Queda ir de las estrellas al Ser como lo hacían los protagonistas del mundo precolombino (Quirce Balma, Del Ser..., 2011). Sin embargo, esta tarea parece que debe ser llevada por otra vía, en atención a modernas cacerías de brujas ${ }^{36}$.

36. "Dice Charlton (2006) que el retorno de la humanidad al animismo a través de los alucinógenos y la adopción de patrones de pensamiento menos severos o menos dañinos, puede que nos conlleve un sentimiento curativo de andar siempre acompañado. Una alternativa a un ego aislado, alienado y enajenado. Dicho evento tendiendo, como en los grupos aborígenes tribales, a disminuir y quizás eliminar las neurosis neogénicas y su ansiedad de separación o angst. Desde luego es idealista pensar a un retorno del uso de alucinógenos mundialmente, si aún estos yacen clasificados como drogas de Horario I (Schedule I) de la DEA y otros organismos miopes y astigmáticos que debe soportar la humanidad. Es necesario hablar de quizás una metodología de meditación y contemplación, que además de no estar prohibidos sean de fácil acceso al ser humano explorador" (Quirce, El tugurio..., 2011b). 
La meditación y la mística evidentemente son el medio más viable en vista de la moderna Inquisición, satanizadora de la visión de Xochipilli, Dios Príncipe de las Flores. En todo caso, el sabio de los enteógenos no por eso deja de apelar al Omega, que es visto en medio de esta tierra de desigualdades sociales. En donde no hay libertad para ocurrir y ser para ocurrir y seguir siendo..., ni aun la mal llamada libertad de mercado, en la que lo único predominante son los seguidores vándalos de Mercurio por el daño ajeno: ahí no hay libertad ${ }^{37}$.

\section{El profetismo de Quirce Balma}

El profetismo de Quirce Balma parte de una pneumatología, de raigambre teilhardiana, aunque sostiene con originalidad que el cambio del Milieu materialista al Milieu teológico se logra con la visualización del Omega, dada en la confluencia de Ciencia y Religión que valora la cuestión chamánica, los enteógenos y los estados alterados

37. Según he visto ello no implica el abogar por un estatismo aplastador de la dignidad humana, como mal que puede hacerse en detrimento de lo que bien se cosecha por el trabajo creativo de las personas, crimen de los colectivos materializadores-desespiritualizadores tanto de izquierda como de derecha. Más bien señala la hipocresía de llamar libertad lo que no da un ganar-ganar, sino un perder-ganar. En dicho caso cuán necesario es descosificar al hombre. de conciencia. En este sentido, el discurso profético propone la necesidad de espiritualidad ante el proceso de materialización en el que se sumerge la civilización actual. Por tanto, a este profetismo caben las siguientes consideraciones:

a. El Espíritu da a luz a la Materia y esta al Espíritu: actuar de Xochipilli, Dios Príncipe de las Flores. Alusión al chamán y su herbología: puerta a la adivinación y magia, que no desatienden los ancestros, la cacería y la medicina. La cura de sentirse siempre acompañado y del recuerdo presente de los que han sido y son parte en el fruto del presente para el mañana; la toma en esperanza de lo necesario para la vida por lo que ha sido manifestado en presencia o ausencia: aquello de lo que no se desea por lo otro necesario. Vaticino nutrido de lo que ha sido a la luz del recuerdo despertado por un dios ingerido. Magia: todo ello lo es.

b. Danza, rito y canto que invocan la lluvia como hoy se desea el agua potable en medio de las contaminadas cuencas aplastadas de cemento y la ausencia de los hijos del bosque: árboles captadores del preciado líquido. Ritmo necesario en el buen 
deseo como padre del sueño que impide los viajes fallidos.

c. Colores en las direcciones de un ser como entidad de rosas de los vientos, entre Navajos y Aztecas que en graphos de piedra, cerámica y otras formas de lenguaje, invitan al "estadio de la conciencia en medio del estado de la conciencia de ser/ antiser" (Quirce, El Señor..., 1994: 1994). Diseños paralelos al áspid alada de Quetzalcóatl como al tiempo que es uno por Xochipilli, Dios Príncipe de las Flores. Lo sacro del ocurrir como en calendario de "horas" de Europa medieval, mándalas de Oriente y relojes espirituales y alucinatorios de las Américas (Quirce, El Señor..., 1994: 152).

d. Puertas al mundo de los dioses: educación para hijos de la Materia necesitados de metamorfosis por el Omega entrevisto por el chamán. Saber para poder más y más como defensa contra los malvados chamanes y espíritus malignos, cuerpos e ideas de guías de ciegos que visten la piedad y esconden su maldad (Mt. 23, 27-28).

e. Fin del Milieu materialista por el advenimiento del Reino de los Cielos, Noosfera convergiendo al Omega a pesar de la cacería de brujas de la DEA, del espejismo en manos del ladrón y de las seductoras frases prometedoras del cielo por cruzar los brazos creadores.

f. Cielo visto donde no hay libertad, la necesidad ecuménica ante las mentiras de una sociedad desespiritualizada y materializadora, que permite al amparo del Estado el sacrificio de la Vida en nombre del mal llamado libre mercado o del socialismo como esperanza de las naciones.

\section{Conclusiones de la expedición}

Vista el agua profunda queda la sensación de temor y gozo simultáneos. Como zarza ardiente, queda el recuerdo de ser para ser.

Todo converge en el Ser.

a. La pneumociencia es y no es Ciencia y Religión, en la medida que es fruto de ambas, distinto como producto al árbol.

b. El Espíritu aparece como caos originario y nacido del cosmos de la Materia matrix. De ahí la importancia de sentir, saborear, ver, saber la Materia.

c. Lo numinal logrado por los estados alterados de conciencia constituye la posibilidad: el Espíritu como hijo de la Materia como lo que es. La presencia en la ausencia como lo fenomenal en lo numinal y hacia lo numinal. 
d. Existe una linealidad pneumocientífica entre Teilhard de Chardin y Quirce Balma, aunque este último va más allá con el profetismo.

e. Ante la cosificación humana surge la imperativa necesidad de despertar hacia una vinculación con el todo, sin caer en la enajenación mecanicista del materialismo. Es fundamental una interrelación de seres orgánicos, planetarios, en evolución omegaizadora. La pneumociencia logra esta interrelación, pues en ella converge la Ciencia y la Religión para entrever el Omega, polo de atracción por el que se descosifica y espiritualiza el ser humano.

f. Corresponde a la teología en cuanto disciplina que estudia y vive el punto Omega, partir de esta pneumociencia.

\section{Bibliografía citada}

Avendaño H., F. (2002). Introducción a la Teología. San José: EUNED.

Brenes M., J. (2003). Del mito. San José: Perro Azul.

Brenes M., J. (2002). El Diablo en el origen mítico de las pasiones. Revista de Filología y Lingüistica, XXVIII (2):163-170.

Douglas, J. D. (2000, c1982). Nuevo Diccionario Bíblico Certeza. Barcelona, Buenos Aires, La Paz, Quito: Ediciones
Certeza. Recuperado de base de datos en CD ROM [Logos Library System 2.1f], [1995-1999].

Hinkelammert, F. (2003). El asalto al poder mundial y la violencia sagrada del imperio. San José: DEI.

Mena O., F.; Ramírez M., I. \& Rojas, R. (2006). Guía de Estudio para la práctica profesional supervisada, Proyecto de Investigación en Teología. San José: UNED-UNA.

Mohandas, E. (2008). Neurobiology of Spirituality. En: Mental Health, Spirituality, Mind. 6 (10): 63-80.

Quirce Balma, C. (1994). El Señor Dios Príncipe de las flores. Revista de Ciencias Sociales (Universidad de Costa Rica). 65: 149-163.

Quirce Balma, C. (2010). El chamanismo y las drogas enteogénicas/alucinatorias del mundo precolombino. Revista Costarricense de Psicología. 29(43):1-15.

Quirce Balma, C. (2011a). El Milieu Teológico. Semanario Universidad. San José. (2 agosto 2011). Recuperado de Semanario Universidad: http://www.semanariouniversidad.ucr.cr/index.php/ opinion/4254-el-milieu-teologico.html

Quirce Balma, C. (2011b). El tugurio de la Filosofía. Semanario Universidad. San José. (30 agosto 2011). Recuperado de Semanario Universidad: http:// www.semanario.ucr.ac.cr/index.php/ component/content/article/1342Opini $\%$ C3\%B3n/4408-el-tugurio-dela-filosofia-.html

Quirce Balma, C. (2011c). Del Ser a las Estrellas (11 set. 2011). Recuperado de Pensamiento Psicológico/Filosófico 
del Dr. Carlos M.Quirce B.: http:// quircebcm.blogspot.com/

Shûtz, C. (1991). Introducción a la pneumatología. Madrid: Ediciones Secretariado Trinitario.

Teilhard de Chardin, P. (1967). La activación de la energía. Madrid: Taurus.

Teilhard de Chardin, P. (1972). Human Energy. New York: Harcourt Brace Jovanovich, Inc.

Teilhard de Chardin, P. (1974). El fenómeno humano. Madrid: Taurus.

Teilhard de Chardin, P. (2002). El Corazón de la Materia. Santander: Sal Terrae.

Vargas, A. (2011). Entrevista al Dr. Quirce Balma sobre Teilhard de Chardin. (26 de setiembre de 2011). Entrevistador: Alejandro Vargas Carranza. San José.

\section{Bibliografía de consulta}

Alves, R. (1980). La teología como juego. Buenos Aires: Ediciones La Aurora.
Bueno, G. (1995). Textos de Gustavo Bueno. Recuperado de Fundación Gustavo Bueno: http://www.filosofia.org/aut/ gbm/1995qc.htm

Campos N., L. (2009). La macroestafa del SIDA y el mito de la transmisión sexual. España: Planeta Matrix.

Quirce Balma, C. (1994). Hacia una teoría de la personalidad de la conciencia. Revista de Ciencias Sociales (UCR). 65: 147-161.

Quirce Balma, C. (2009). Reflexiones psicológicas y filosóficas de una nación en crisis. [Libro sin publicar]. San José: Universidad de Costa Rica.

Quirce Balma, C. (2011). El modelo del arriba y debajo de la conciencia: Análisis etnopsicofarmacológico del uso de plantas enteogénicas. Revista Reflexiones. 90(1): 95-214.

Quirce Balma et al. (2010). Los alucinógenos: su historia, antropología, química y farmacología. Revista Psicogente, 13(23): 174-192. 